\title{
PEMANFAATAN TEKNIK HIDROPONIK ALTERNATIF BAGI RPTRA PONDOK KELAPA BERSERI
}

\author{
Arief Pambudi ${ }^{1 *}$, Nita Noriko ${ }^{1}$, Yunus Effendi ${ }^{1}$, Risa Swandari Wijihastuti ${ }^{1}$ \\ ${ }^{1}$ Program Studi Biologi, Fakultas Sains dan Teknologi, Universitas Al Azhar Indonesia, \\ Jalan Sisingamangaraja, Kompleks Masjid Agung Al Azhar, Kebayoran Baru, Jakarta 12110 \\ Email Penulis Korespodensi: pambudi@uai.ac.id
}

\begin{abstract}
Abstrak
Salah satu masalah produksi pangan di Indonesia khususnya di daerah perkotaan adalah terbatasnya area pertanian. Hidroponik dapat menjadi satu solusi untuk masalah ini. Hidroponik umumnya menggunakan formula nutrisi AB-Mix yang terkadang masyarakat sulit mendapatkannya. Bahan alternatif yang memiliki potensi sebagai sumber nutrisi hidroponik adalah air sisa pencucian beras. Ruang publik terpadu ramah anak (RPTRA) Pondok Kelapa Berseri merupakan suatu komunitas yang dapat direkomedasikan untuk produksi sayuran daerah urban khususnya di wilayah Pondok Kelapa, Jakarta Timur. Hasil kegiatan menunjukkan bahwa penggunaan air beras sebagai medium hidroponik memiliki potensi untuk dikembangkan walaupun penambahan konsentrasi air beras masih perlu dilakukan. Sosialisasi dan sharing pengalaman dengan masyarakat dilakukan pada 50 peserta sekitar RPTRA dan mendapat respon yang baik. Pengurus RPTRA berharap kegiatan seperti ini dilakukan periodik dan disinkronkan dengan jadwal kegiatan PKK di RPTRA Pondok Kelapa lebih banyak orang mendapatkan manfaatnya.
\end{abstract}

Kata kunci: Hidroponik, Media Tumbuh Hidroponik, Media Alternatif Hidroponik

\begin{abstract}
One problem of food production in Indonesia, especially in urban areas is the limited area of agriculture. Hydroponics can be a solution to this problem. Hydroponics generally uses the AB-Mix nutritional formula, which is sometimes difficult to get. Alternative material that potential as a hydroponic nutrient source is residual rice washing water. RPTRA Pondok Kelapa Berseri is a community that can be recommended to vegetable production in urban area, especially in the Pondok Kelapa, East Jakarta. The results of the activity indicate that the use of rice water as a hydroponic medium has the potential to be developed even though additional concentrations of rice water still need to be done. Socialization and sharing experiences with the community were carried out on 50 participants around RPTRA and received good responses. RPTRA hopes that activities like this will be conducted periodically and synchronized with the PKK schedule at RPTRA Pondok Kelapa, so more people will get the benefits.
\end{abstract}

Keywords: Hydroponic, Hydroponic Medium, Hydroponic Alternative Medium

\section{PENDAHULUAN}

Salah satu permasalahan produksi pangan di Indonesia, khususnya di daerah perkotaan ialah terbatasnya lahan pertanian. Pemanfaatan lahan yang terbatas perlu dilakukan untuk meningkatkan produksi pangan. Sistem hidroponik merupakan salah satu cara untuk meningkatkan hasil produksi pangan pada lahan terbatas. Aplikasi hidroponik memiliki berbagai keuntungan, antara lain dapat diatur asupan hara bagi tanaman, dapat menkonservasi air dan hara, pertumbuhan tanaman relatif lebih cepat, penggunaan pestisida minimal, tidak perlu menggunakan herbisida, mudah mengamati 
perakaran, dan dapat dilakukan pada kondisi ekstrim dan minim lahan (Texier, 2015).

Komunitas yang berpotensi untuk pengembangan produksi sayuran adalah ruang publik terpadu ramah anak (RPTRA) Pondok Kelapa Berseri. Kawasan ini terletak di kawasan Pondok Kelapa, Jakarta Barat dan mulai beroperasi sejak tahun 2017. Keberadaan RPTRA di kawasan kelurahan Pondok Kelapa menjadi sarana yang sangat baik untuk berbagai kegiatan komunitas dan organisasi masyarakat seperti pengurus RW, Karang Taruna, serta PKK. Beberapa kegiatan yang sudah rutin berjalan di RPTRA Pondok Kelapa Berseri antara lain pelatihan futsal, taekwondo, karate, menari, melukis, baca tulis Al Quran, hingga tanaman obat keluarga (Toga). Produksi sayursayuran sudah mulai untuk tanaman cabe dan terong, namun masih belum digarap dengan serius. Pengembangan dan produksi sayuran hijau masih besar peluangnya, terlebih dengan penerapan hidroponik.

Umumnya, teknik hidroponik menggunakan nutrisi berupa formula cair A dan B yang biasa disebut dengan pupuk AB Mix. Nutrisi AB-Mix mengandung unsur makro dan mikro yang dibutuhkan tanaman. Namun, terkadang akses memperoleh media AB Mix masih menjadi kendala di masyarakat. Oleh sebab itu perlu dicari alternatif lain yang mudah diperoleh sebagai medium untuk menanaman menggunakan hidroponik.

Salah satu bahan dengan kandungan nutrisi yang mudah diperoleh, namun belum banyak dimanfaatkan adalah sisa cucian air beras (Wulandari, 2012). Sisa cucian air beras merupakan hasil buangan yang berasal dari suatu proses produksi baik industri maupun domestik (rumah tangga) yang tidak memiliki nilai ekonomis lagi. Namun dalam sisa cucian beras mengandung banyak nutrisi yang terlarut di dalamnya yaitu $80 \%$ vitamin $\mathrm{B} 1,70 \%$ vitamin B3, 90\% vitamin B6, 50\% mangan, 50\% fosfor, $60 \%$ zat besi (Nurhasanah et all, 2011).

Selain itu, perangkat hidroponik profesional umumnya menggunakan bahan yang relatif mahal. Namun, sebenarnya penggunaan botol bekas dapat dimanfaatkan sebagai alternatif untuk tempat menanam sayuran secara hidroponik. Pemanfaatan bahan-bahan bekas ini dapat menjadi salah satu cara untuk upaya pengurangan sampah melalui aktivitas daur ulang.

Kegiatan ini dilakukan dalam rangka sosialisasi dasar teknik hidroponik dan penerapan media alternatif sebagai sumber nutrisi tanaman. Diharapkan masyarakat sekitar RPTRA memperoleh tambahan pengetahuan mengenai hidroponik dan dapat menerapkannya untuk menghasilkan sayuran hijau untuk kebutuhan gizi.

\section{METODE PELAKSANAAN}

Kegiatan dilakukan pada 28 Maret sampai 2 Mei 2018. Bahan-bahan yang digunakan adalah benih sawi, air beras, Rockwool, Kain flannel, Nutrisi AB Mix. Peralatan yang dipakai TDS Meter, Wadah Semai, $\mathrm{pH}$ meter, bak penampung larutan nutrisi, selang penghubung, aerator, netpot, sterofoam, kamera, penggaris, alat tulis.

Langkah kerja dilakukan melalui persemaian bibit, pembuatan larutan nutrisi, pemindahan media, serta pemeliharaan, dan kegiatan sosialisasi.

Persemaian Bibit. Bibit diletakkan pada rockwool. Rockwool memiliki 18 lubang, semua lubang tersebut diisi dengan bibit sawi. Setiap lubang diisi dengan 1 bibit. Rockwool yang sudah diisi dengan bibit diletakkan pada wadah semai lalu ditutup dan didiamkan selama 24 jam. Tutup wadah semai dibuka apabila bibit sudah disemai dalam keadaan tertutup/gelap selam 24 jam. Wadah semai dibiarkan terbuka sampai bibit mengalami pertumbuhan daun ke4.

Pembuatan Nutrisi AB mix. Wadah diisi dengan $900 \mathrm{ml}$ air keran kemudian dimasukkan nutrisi A dan B pada masing-masing wadah. Masing-masing wadah ditambahkan air keran sampai wadah bervolume $1000 \mathrm{ml}$. Wadah nutrisi A dan B mix dipindahkan ke dalam 6 botol berbeda. Masing-masing botol memiliki $330 \mathrm{ml}$ untuk nutrisi A dan B.

Pemindahan Media dan Pemeliharaan. Bibit sawi yang sudah mengalami pertumbuhan daun ke-4 siap untuk dipindahkan ke media. Bak penampung sebanyak dua buah disiapkan untuk media air beras dan nutrisi $\mathrm{AB}$ mix. Bak penampung yang berisi media air beras memiliki perbandingan 3:1, air beras sebanyak $900 \mathrm{ml}$ sedangkan air keran sebanyak $2100 \mathrm{ml}$. Bak penampung nutrisi $\mathrm{AB}$ mix berisi $3000 \mathrm{ml}$ air keran (3L) dan ppm nutrisi $\mathrm{AB}$ mix ialah 811 ppm. Penggunaan nutrisi $A B$ mix pada media disesuaikan dengan referensi jurnal. Pengamatan setelah pemindahan media 
dilakukan dengan melakukan pengecekan ppm dan $\mathrm{pH}$ setiap media dan penggantian media setiap 1 minggu sekali. Pada penggantian media air beras yang kedua, perbandingan media diubah menjadi 1:1 yaitu $1500 \mathrm{ml}$ air beras dan $1500 \mathrm{ml}$ air keran.

Kegiatan sosialisasi. Sosialiasi dilakukan pada dua kelompok audiens, yaitu pada anakanak dan pada ibu-ibu sekitar RPTRA Pondok Kelapa Berseri. Sosialisasi dilakukan melalui presentasi mengenai hidroponik dan dilanjutkan dengan pembuatan perangkat hidroponik sederhana.

\section{HASIL DAN PEMBAHASAN}

\section{Percobaan alternatif air beras sebagai media tumbuh}

Hasil pengamatan menunjukkan bahwa pertumbuhan tanaman yang diberi nutrisi dengan $\mathrm{AB}$ mix memiliki pertumbuhan yang lebih pesat dibandingkan dengan diberi nutrisi berupa air beras saja walaupun secara statistik tidak berbeda nyata kecuali pada pengamatan 13 hari setelah perlakuan (Gambar 1)

Lebih rendahnya pertumbuhan tanaman menggunakan air beras dapat disebabkan oleh rendahnya total kadar nutrisi yang terkandung pada air beras dibandingkan dengan $\mathrm{AB}$ mix (Tabel 1). Diketahui ternyata nilai TDS pada media AB Mix mencapai lebih dari 5 kali nilai TDS pada media air beras. Hal ini menunjukkan bahwa sebenarnya secara aktual, larutan AB mix memang lebih menyediakan hara terlarut lebih kaya dibandingkan dengan air beras.

Selain nilai TDS, nilai $\mathrm{pH}$ memberikan cerminan yang mampu menjelaskan mengapa pertumbuhan pada $\mathrm{AB}$ mix lebih baik dibandingkan air beras. Nilai rataan $\mathrm{pH}$ pada $\mathrm{AB}$ mix berkisar di nilai 6.8 , sedangkan air beras di kisaran yang lebih basa, sekitar 7.8.

Serapan nutrisi pada tanaman secara umum membutuhkan $\mathrm{pH}$ optimum di kondisi yang relatif asam, yaitu sebesar 5.5-6.5 (Taiz \& Zeiger 2010). Menurut Syariefa et al. (2014), tanaman sawi akan tumbuh dengan baik pada kondisi nutrisi dengan TDS 800-1500 ppm dengan nilai $\mathrm{pH}$ yang berkisar antara 5.5-6.5. Umumnya derajat keasaman $(\mathrm{pH})$ suatu larutan nutrisi untuk budidaya hidroponik berada pada kisaran 5,5-7,0 atau bersifat asam. Pada kisaran tersebut daya larut unsur-unsur hara makro dan mikro sangat baik. Bila nilai $\mathrm{pH}$ kurang dari 5,5 atau lebih dari 7,0 maka daya larut unsur hara tidak sempurna lagi. Bahkan, unsur hara mulai mengendap sehingga tidak bisa diserap oleh akar tanaman (Kamaraj et all, 2012). Kisaran pH lebih dari 7 termasuk terlalu tinggi untuk sayuran yang dapat menyebabkan unsur-unsur hara larutan nutrisi menjadi sukar larut dan tidak tersedia bagi tanaman. Dalam larutan nutrisi yang memiliki nilai $\mathrm{pH}$ pada rentang optimal, unsur-unsur hara menjadi mudah larut dan cukup tersedia bagi tanaman sehingga dapat diserap dan dimanfaatkan untuk pertumbuhan.

Dengan kondisi tanaman yang diamati menggunakan 2 perlakuan media, diperoleh informasi bahwa pengaturan terhadap media cair menjadi hal yang sangat penting, terutama terkait $\mathrm{pH}$ dan nilai TDS. Air beras sebenarnya memiliki potensi yang bagus sebagai media cair, namun masih perlu dilakukan penambahan konsentrasi air beras agar nilai TDS meningkat sesuai dengan TDS optimum. Pengaturan nilai $\mathrm{pH}$ juga perlu dilakukan agar larutan dalam kondisi sedikit asam, sehingga hara yang terlarut tersedia dan dapat diserap oleh tanaman.

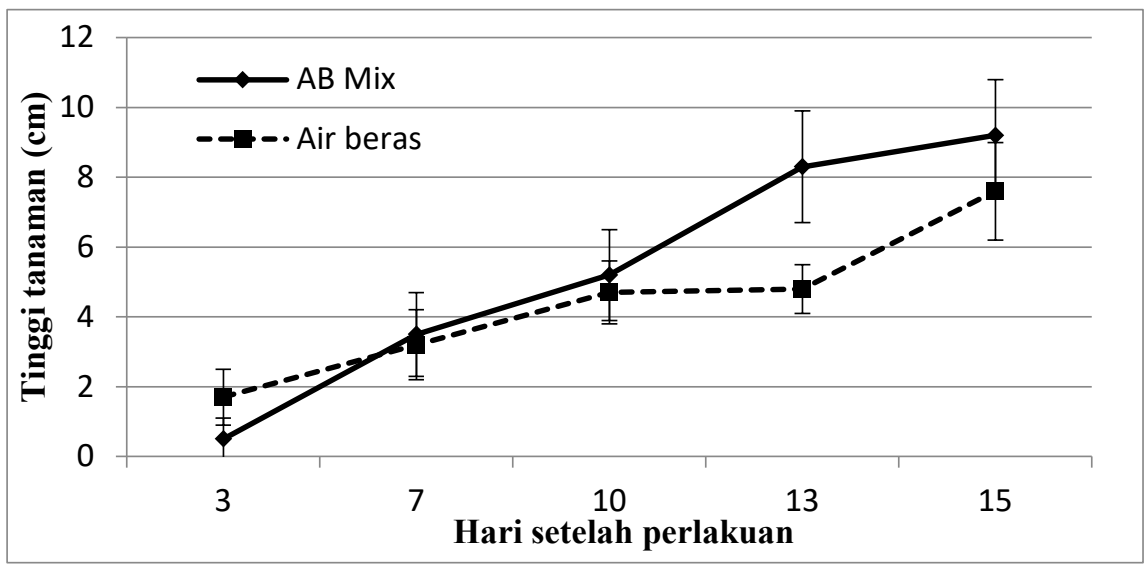

Gambar 1. Pola pertumbuhan tanaman sawi pada kedua perlakuan 
Tabel 1. Perbandingan nilai kadar nutrisi dan $\mathrm{pH}$ pada kedua kondisi media.

\begin{tabular}{lccc}
\hline \multicolumn{1}{c}{ Parameter } & Media AB Mix & Media air beras & Optimum \\
\hline Rataan nilai TDS (ppm) & 1083 & 190 & $800-1500$ \\
Rataan nilai pH & 6.8 & 7.8 & $5.5-6.5$ \\
\hline
\end{tabular}

\section{Sosialisasi hidroponik pada masyarakat}

Sosialisasi hidroponik dilakukan di RPTRA Pondok Kelapa Berseri, dengan target ibu-ibu rumah tangga dan anak-anak. Ibu rumah tangga dijadikan target agar memiliki pengetahuan dasar mengenai hidroponik agar dapat menerapkan minimal di area RPTRA, yang salah satu programnya berupa Aksi Cita Tanaman. Sedangkan anak-anak dijadikan target karena sebagai bentuk edukasi awal untuk mulai mengetahui pentingnya konsumsi sayuran serta merawat tanaman. Hasil sosialisasi disajikan pada Tabel 2 dan suasana sosialisasi pada Gambar 2.

Sosialisasi pada anak-anak dilakukan dengan menunjukkan perangkat hidroponik, lalu mereka melakukan pembuatan perangkat hidroponik sederhana menggunakan botol bekas air mineral. Selanjutnya dilakukan games untuk memancing kecintaan anak-anak terhadap pelestarian lingkungan. Antusiasme dari anakanak pengunjung RPTRA terhadap acara seperti ini sangat tinggi.

Sosialisasi pada ibu-ibu sekitar RPTRA dilakukan dengan sedikit penjelasan mengenai hidroponik dan dilanjutkan dengan aktivitas pembuatan media tanam, menyemai benih, dan memindahan bibit yang sudah berkecambah ke perangkat hidroponik sistem wick. Sama seperti sosialisasi pada anak-anak, sosialisasi pada ibuibu mendapat sambutan yang juga baik. Pihak pengurus RPTRA dan RW juga berharap kegiatan seperti ini dapat dilakukan secara periodik dan diintegrasikan dengan kegiatan ibu PKK sehingga lebih banyak yang mendapat manfaat.

Tabel 2. Gambaran proses dan hasil kegiatan sosialisasi kepada masyarakat

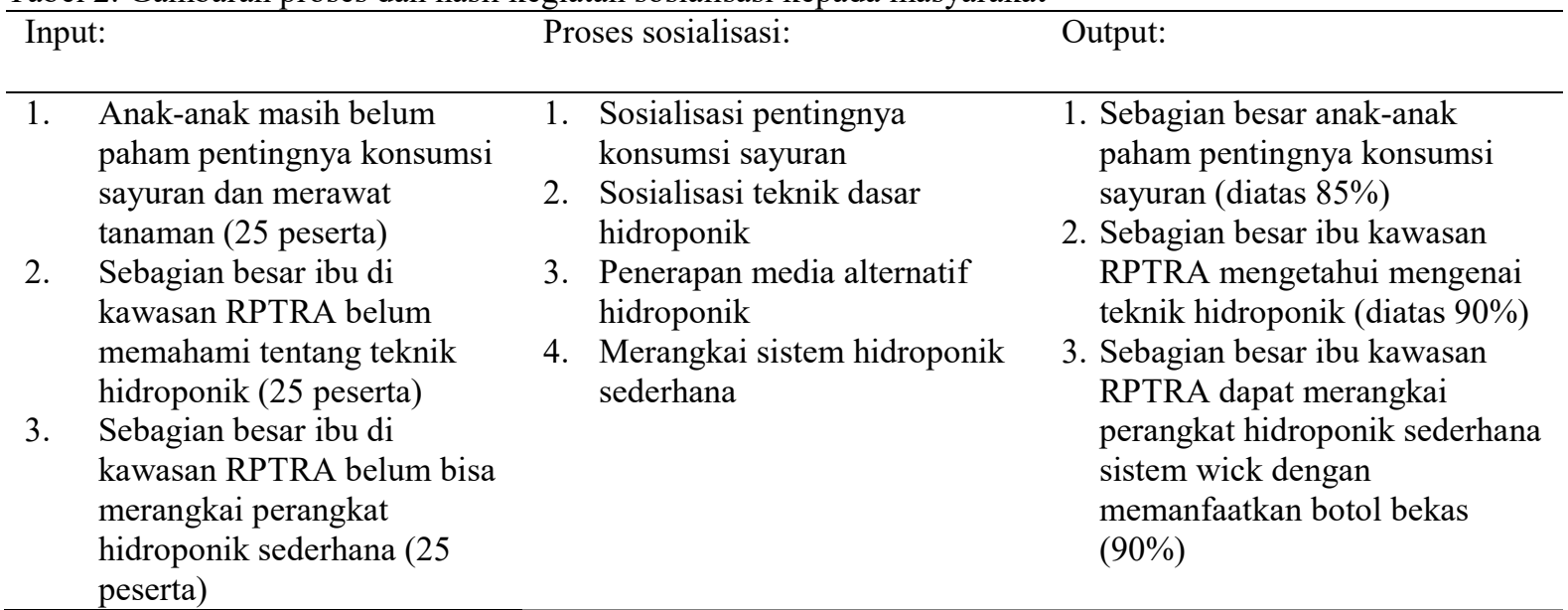
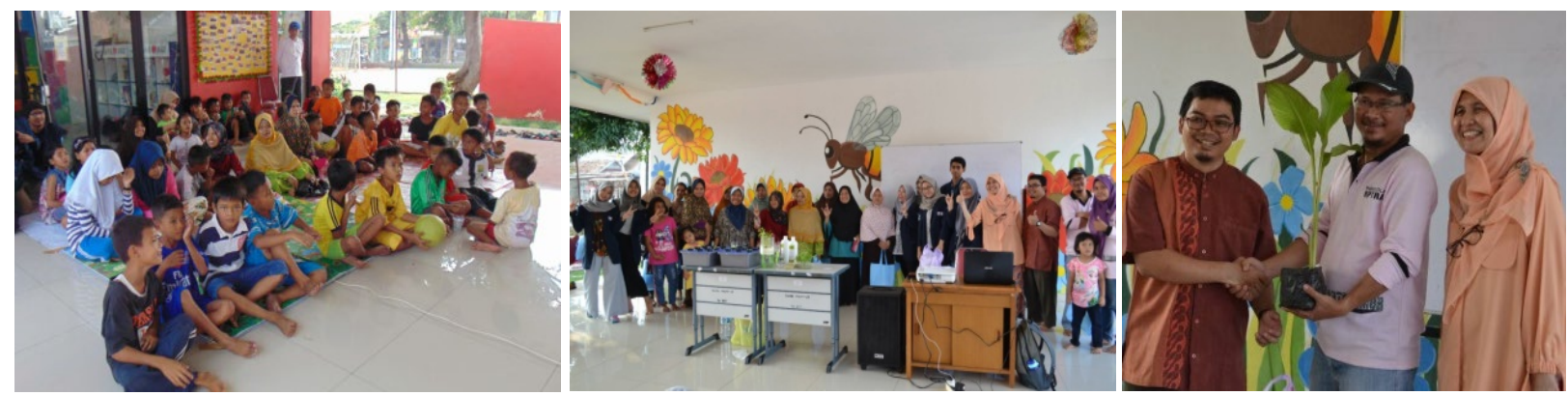

Gambar 2. Beberapa dokumentasi saat sosialisasi hidroponik kepada masyarakat 


\section{SIMPULAN DAN SARAN}

Penggunaan air beras sebagai medium hidroponik memiliki potensi untuk dikembangkan namun masih perlu dilakukan penambahan konsentrasi air beras agar nilai TDS sama dengan nilai TDS AB mix. Sosialisasi dan sharing pengalaman dengan masyarakat dilakukan pada 50 peserta (25 anakanak dan 25 ibu-ibu) sekitar RPTRA dan mendapat respon yang baik. Pengurus RW dan RPTRA berharap kegiatan seperti ini dilakukan periodik dan disinkronkan dengan jadwal kegiatan PKK di RPTRA Pondok Kelapa.

\section{UCAPAN TERIMA KASIH}

Ucapan terima kasih kepada LP2M UAI yang telah mendanai kegiatan ini melalui skema Pengabdian Masyarakat Berbasis Riset tahun 2018.

\section{DAFTAR PUSTAKA}

Cornicopia Institute. (2015). The Organic Hydroponic Dichotomy: Can Soil-less Growing System be "Organic"? A White Paper.

Kamaraj M, Sivaraj R, Priya S, Jansi L, Manjudevi M. (2012). Uptake of mineral elements by Brassica juncea and its effects on biochemical parameters. Adv. Appl. Sci. Res 3(2):1039-1044

Nurhasanah YS, Nailufar N, Pradana R, Nurhayati A, Muhammad I. (2011). Potensi Limbah Air Cucian Beras sebagai Media Perbanyakan Bakteri Probiotik Tanaman. PKM-Penelitian. IPB Press.

Riyani C. (2017). Metode penyimpanan bahan olah karet (bokar) oleh pedagang pengumpul tingkat usahatani di puruk cahu kabupaten murung raya. Jurnal Budidaya Tanaman Perkebunan Politeknik Hasnur. 3 (2).42-80.

Syariefa E, Duryatmo S, Angkasa S, Apriyanti RN, Raharjo AA, Rizkika A, Rahimah DS, Titisari A, Setyawan B, Vebriansyah R, Fadhilah R, Nugroho H, Awaluddin M. 2014. Hidroponik Praktis. Jakarta: PT Trubus Swadaya.

Taiz L, Zeiger E. (2010). Plant Physiology 5 ed. Sunderland, Massachusetts: Sinauer Associates Inc., Publishers

Texier W. (2015). Hydroponics for Everybody. Paris: Mama Publishing

Wulandari CGM. (2012). Pengaruh Air Cucian Beras Merah dan Beras Putih terhadap Pertumbuhan dan Hasil Selada (Lactuca sativa L.). Yogyakarta: Skripsi. Fakultas Pertanian Universitas Gadjah Mada

Wright P. (2004). Totally Organic Hydroponics. Organiponics 